\title{
The use of neural networks and a genetic algorithm for modeling the innovative environment of enterprises
}

\author{
Svetlana Sviridova ${ }^{1}$, Elena Shkarupeta ${ }^{1, *}$, and Olga Dorokhova ${ }^{2}$ \\ ${ }^{1}$ Voronezh Technical State University, 14, Moskovsky Av., Voronezh, 394026Russia \\ ${ }^{2}$ Moscow Suvorov Military School, 11, Twisting Journey, Moscow, 129329, Russia
}

\begin{abstract}
The purpose of this paper is to develop methodological tools for building the innovative environment of enterprises using the genetic algorithm and neural networks. The paper analyzes and highlights the advantages of genetic algorithms in the search for optimal solutions compared to classical methods. The scheme of construction of each step of the genetic algorithm is described in detail; the scheme of the presentation of artificial neural network data in key factors of innovative development of enterprises is given. The aspects of using neural networks of attractors and a genetic algorithm for modeling the processes of the innovative environment of enterprises are considered. The key problem of introducing effective industrial innovations is the lack of a favorable climatic environment that stimulates the creation of innovations that ensure the growth of global competitiveness, labor productivity and the quality of life of the population. The result of the study is the formation of a model of the innovative environment of enterprises based on the use of neural networks and a genetic algorithm.
\end{abstract}

\section{Introduction}

The authors adhere the view of group of researchers [1], in accordance to which it seems possible to speak about new approach, in frameworks of which it states that the institutes of regional business environment have certain energy (or energy potential).

From our point of view the submitted approach can be adjusted to problematics of this research and apply the concept of energy field not only to institutional environment, but general development environment as edges sets of development environment pyramid of industrial complexes (institutes, knowledge, culture, infrastructure, markets), considered in the first chapter of thesis research. Then it can be stated that the environment drivers set forms local energy field where innovative systems function and which affects parameters of their activity. Possibility of influence of power (energy) innovative field on innovative system is determined by the fact that the last has certain potential (charge). Energy potential of industrial complexes system is - its innovative activity, need and ability to generate innovations and others. Parameters of energy charge of certain industrial complexes system

${ }^{*}$ Corresponding author: 9056591561@mail.ru 
are determined by the combination of determinants of its innovative potential: the availability of resources, degree of risk appetite, focusing on the approaching of results and others. But the process of innovative activity is accompanied with facing of limitations, which are imposed by the development environment, as the result of what the innovative system is influenced with certain energy affect and develops in certain direction.

\section{Materials and methods}

In terms of synergetic modelling we can speak about the fact, that in frameworks of power (energy) field it is possible the occurrence of as it is called drivers-attractors, i.e. energy space generating by drivers, which affection cumulative and complementary impels (forces) the innovative systems for choice of the certain activity direction.

In other words, driver-attractor zone represents by itself a kind of energy field (being the most active part of power (energy) field of the development environment of industrial complexes), having certain vectorial induction, affecting innovative systems with sufficient force and prevails them on functioning and developing in certain direction and values range.

Any configuration of innovative environment generates different drivers-attractors zones depends on energy field value. In most general form there can be identified positive, neutral and negative drivers-attractors zones.

- Positive drivers-attractors zone is a kind of energy space, being generated by certain drivers combination of industrial complexes development environment the cumulative and complementary affect of which prevails innovative system for choice of positive direction of functioning;

- Negative drivers-attractors zone prevails innovative systems for unproductive and destructive functioning directions.

In this work by modelling of networks of drivers-attractors of industrial complexes development environment based on reviews of neurosimulators for PC and cluster computing $[2,3]$ was chosen computer neurosimulator SimBrain (http://simbrain.net/index.html). The usage examples of nerusimulator SimBrain for different types of neural networks are introduced on image 1 and image 2 below.

\section{Results}

Taking into account the modern realias and tendencies it is worthy to consider the innovative environment at following levels [4]:

- level L1: mega- (global level);

- level L2: meso-level 1 (mega-macro);

- level L3: macro- (national level of country, state);

- level L4: meso-level 2 (macro-micro);

- level L5: micro- (enterprise level).

Innovative environment levels are distinct in located in them subjects and objects of carrying out of innovative activity, localization degree and scales. Coordinated structural and functionally, they are forming based and intermediate (meso-) levels of vertical and horizontal interactions. Meso-spaces serves as intermediate layers and at the same time serve as generators of innovative environment based levels changes generators [5].

Experts BCG for purposes of structuring of terms of innovative environment have developed the innovative development pyramid, or briefly - the pyramid of innovations. From the point of view of authors in conditions of digitization it is worthy to make actual the innovative environment pyramid BCG due to matrix of the National technological 
initiative (NTI) - key element of National technological initiative, determining the logic of formation of interaction between all its participants [6].

In the center of focus of made actual innovative pyramid are six layers [7, 8]:

1. Institutions: based conditions for public life.

2. Knowledge (talents): conditions for appearance of researches.

3. Culture: conditions for development.

4. Technologies, platforms and services: directions for development.

5. Infrastructure: conditions for activity.

6. Market: commercialization.

An important indicator is degree of sustainability of pyramid which can be determined due to parameters variations indexes (institutes, knowledge, culture, technologies, infrastructure, markets) within frameworks of each innovative environment. Thus for target state of innovative environment innovative pyramid must be balanced.

The essence of innovative environment formation is the reaching of global competitive ability and outstripping development of social-economics system, maximization of labor productivity, whereof it results that cross-boarder effective interaction of business, scientific-educational community and state, development of high-technologies business based on traditional and high-technologies markets, increase of competitive ability on global market it is worthy to consider as the main aspect of goal-setting of innovative environment formation at all levels [9]. Under conditions of fourth industrial revolution the set of locomotive branches and with it connected technologies and scientific foundations is changing. Key meaning acquire technologies directed neither to production nor to distribution of goods and services but to the human self. These are biotechnologies, new medicine, robotechnics, nanotechnology, cognitive technologies, high-human technologies, new use of natural resources and line of others. All of this is much more orientated to human than technological priorities of previously structure. Nucleus of six technological structures may become NBIC-convergence. Under NBIC-technologies (Nano-Bio-InfoCogno-technologies) there are deemed breakthrough innovative technologies in the field of convergence of nanotechnology, ICT, biotechnologies and cognitive technologies. Many modern new technologies are located at joining point of group NBIC, for example, construction of cellular and tissue structures (nano+bio), new informational interfaces (info $+\operatorname{cogno}$ ), bioinformatics (nano+info+bio).

Let us show drivers-attractors networks modelling of industrial complexes development environment in neurosimulator SimBrain at time of $\mathrm{t}=500$. 


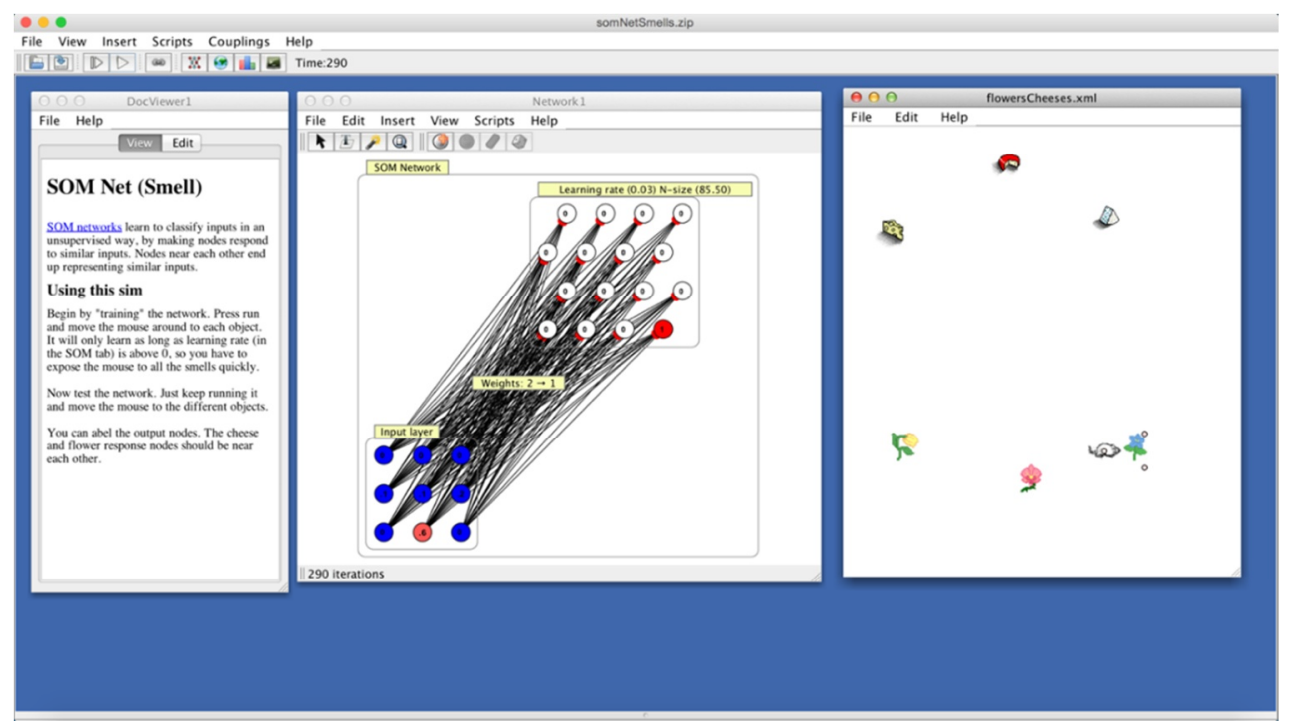

Fig. 1. Kohonen Self-organizing map (in English- Self-organizing map — SOM) — neural network with study without teacher, implementing the task of visualization and clustering (Source: http://simbrain.net/index.html).

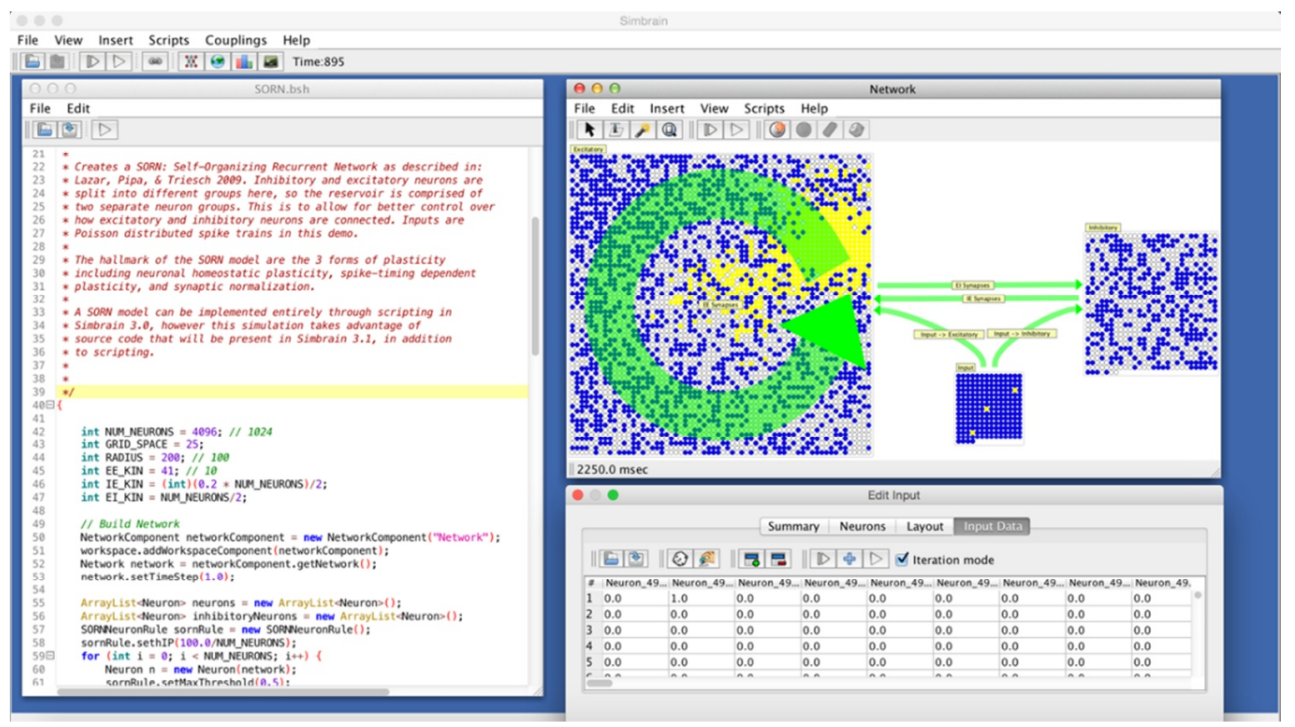

Fig. 2. SORN: Self-organizing current neural network (Lazar, Pipa \& Triesch, 2009) (Source: http://simbrain.net/index.html).

On the image 3 there are positive drivers-attractors zones of industrial complexes development environment colored in red color, neutral are colored in white. It is assumed that there are no negative drivers-attractors in development environment. The energy field size of driver-attractor is set conventional quantitative and is displayed digitally in circle of attractors. The energy field size affects on intensity of coloring of attractors - since light pink till bright red. 


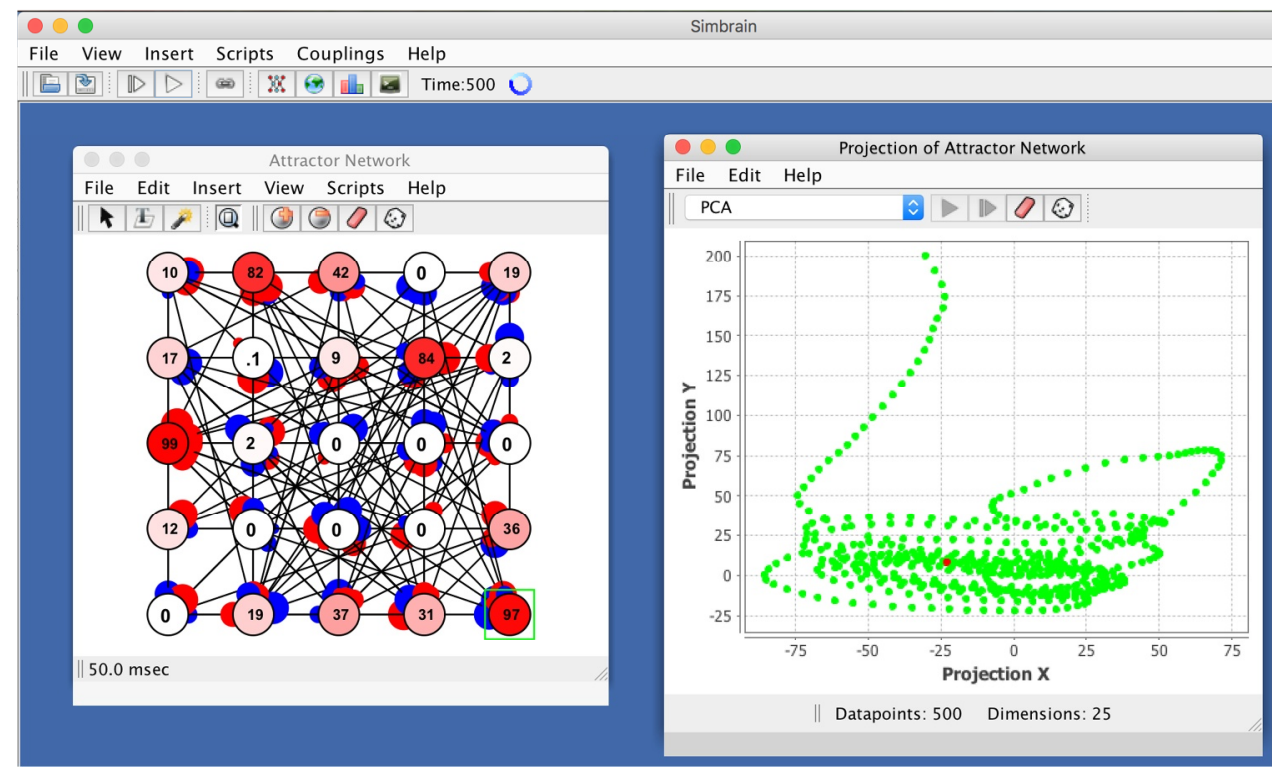

Fig. 3. Drivers-attractors network at the time of $\mathrm{t}=500$ (Source: is developed by authors).

From the image 3 it is seen how changes drivers-attractors energy field, their type and form over time.

In third-dimensional phase space of smooth flow it is arose the Lorenz attractor. Lorenz differential equation system (1) $[10,11,12]$ :

$$
\left\{\begin{array}{c}
\frac{d}{d t} x(t)=-\sigma x(t)+\sigma y(t) \\
\frac{d}{d t} y(t)=-x(t) z(t)+r x(t)-y(t) \\
\frac{d}{d t} z(t)=x(t) y(t)-b z(t)
\end{array}\right.
$$

Defines the three variables time change $\mathrm{x}(\mathrm{t}), \mathrm{y}(\mathrm{t})$ and $\mathrm{z}(\mathrm{t})$, system dynamics is defined by parametric indexes $\sigma, \mathrm{r}$ and $\mathrm{b}$.

For creation of model we will write the Lorenz system by equations in finite decrements $\Delta \mathrm{x}, \Delta \mathrm{y}, \Delta \mathrm{z}$ after output coordinates (Ikonnikova et al, 2015):

$$
\left\{\begin{array} { c } 
{ \frac { \Delta x i } { \Delta t } = \sigma ( y _ { i - 1 } - x _ { i - 1 } ) , } \\
{ \frac { \Delta y i } { \Delta t } = - x _ { i - 1 } z _ { i - 1 } + r x _ { i - 1 } - y _ { i - 1 } } \\
{ \frac { \Delta z i } { \Delta t } = x _ { i - 1 } y _ { i - 1 } - b z _ { i - 1 } }
\end{array} \Rightarrow \left\{\begin{array}{c}
\Delta x i=\sigma\left(y_{i-1}-x_{i-1}\right) \Delta t \\
\Delta y i=\left(-x_{i-1} z_{i-1}+r x_{i-1}-y_{i-1}\right) \Delta t \\
\Delta z i=\left(x_{i-1} y_{i-1}-b z_{i-1}\right) \Delta t
\end{array}\right.\right.
$$

where $\mathrm{i}$ - is number of current point: $\Delta \mathrm{t}-$ is finite decrement in time.

\section{Conclusion}

In the frameworks of developed model there are considered general contours of methodological approach. The development logic assumes furthering development and research of quantitative and qualitative parameters of drivers-attractors zones, drivers energy efficiency of industrial complexes development environment, i.e. the level of drivers energy potential use rationality and so on. The solution of these items allows reaching new theoretical-applied level in solution of applied tasks of industrial complexes development 
environment managing.

Thus it was implemented the modelling of process forecasting of industrial complexes development environment management. However it is worthy to be noticed that the evaluation items and risks management items connected with digital transformation require more detailed and deep researching as conducted researches have shown, at the present time there are absent methodological foundations and methodical tools of evaluation and risks management connected with transformation of industrial complexes development environment.

\section{References}

1. Solodilova N.Z., Malikov R.I., Grishin K. E. Methodological approach to designing of institutional attractors zones of innovative type in regional business environment Vestnik UGNTU. Science, education, economics. Series: Economics. 2017. 1 (19). Access mode: https://cyberleninka.ru/article/n/metodologicheskiy-podhod-kproektirovaniyu-zon-institutsionalnyh-attraktorov-innovatsionnogo-tipa-v-regionalnoydelovoy-srede (access date: 25.04.2018).

2. Shelomentseva I.G., Noskova E.E. Classification and choice of software for working with neural networks within frameworks of medical diagnostic system construction // Modern scientific researches and innovations. 2016. 11. Access mode: http://web.snauka.ru/issues/2016/11/74149 (access date: 11.01.2018).

3. Kryuchin O.V., Kozadaev A.S., Arzamastsev A.A. Review of neurosimulators for PC and clusters systems // Vestnik of Tambovsky university. Series: Natural and engineering sciences. 2012. 17. Access mode: https://cyberleninka.ru/article/n/obzorneyrocimulyatorov-dlya-personalnyh-kompyuterov-i-klasternyh-sistem (Access date: 25.04.2018).

4. A. Lazar, G. Pipa, Triesch J. SORN: A Self-Organizing Recurrent Neural Network. Frontiers in Computational Neuroscience (2009) https://doi.org/10.3389/neuro.10.023.2009

5. A.L. Fradkov, Cybernetical physics: principles and examples (Science, SaintPetersburg, 2003) http://www.mtas.ru/search/search_results_ubs_new.php? publication_id $=18388 \&$ IBLOCK_ID $=10$

6. N.A. Ikonnikova, Modelling and control of dynamic process in problems of evaluation of geological systems state, http://ir.nmu.org.ua/bitstream/handle/123456789/ 146621/CD646.pdf? sequence=1\&isAllowed=y (2015)

7. T. Tolstykh, E. Shkarupeta, Y. Kostuhin, A. Zhaglovskaya, Proceedings of the 31th International Business Information Management Association Conference (IBIMA) (Milan, 2018)

8. T. Tolstykh, N. Kretova, A. Trushevskaya, E. Dedova, M. Lutsenko, Problems and Prospects for Implementing Inter-dimensional and Inter-industry, Projects in Digital Economy, Advances in Intelligent Systems and Computing (2018)

9. N. Serebryakova, T. Ovchinnikova, I. Bulgakova, S. Sviridova, T. Tolstykh, Innovational methods of development of intellectual labor for economy's security, European Research Studies Journal (2017)

10. T. Kolmykova, E. Merzlyakova, V. Bredikhin, T. Tolstykh, O. Ovchinnikova, Problems of formation of perspective growth points of high-tech productions, Advances in Intelligent Systems and Computing (2018) 
11. I. Karapetyants, Y. Kostuhin, T. Tolstykh, E. Shkarupeta, A. Krasnikova, Proceedings of the 30th International Business Information Management Association Conference (IBIMA) (Madrid, 2017)

12. I. Karapetyants, Y. Kostuhin, T. Tolstykh, E. Shkarupeta, E. Syshsikova, Proceedings of the 30th International Business Information Management Association Conference (IBIMA) (Madrid, 2017) 